OPEN ACCESS

Edited by:

Sean P. Collins,

Georgetown University School of

Medicine, USA

Reviewed by: Andrew Wenhua Ju,

The Brody School of Medicine at

East Carolina University, USA

Jonathan W. Lischalk

Georgetown University Medical

Center, USA

*Correspondence:

Rachelle Lanciano

rlancmd@gmail.com

Specialty section:

This article was submitted to

Radiation Oncology,

a section of the journal

Frontiers in Oncology

Received: 21 May 2016 Accepted: 02 August 2016 Published: 23 August 2016

Citation:

Ricco A, Manahan G, Lanciano $R$ Hanlon A, Yang J, Arrigo S, Lamond J, Feng J, Mooreville M, Garber B and Brady L (2016)

The Comparison of Stereotactic Body Radiation Therapy and Intensity-Modulated Radiation

Therapy for Prostate Cancer by NCCN Risk Groups.

Front. Oncol. 6:184.

doi: 10.3389/fonc.2016.00184

\section{The Comparison of Stereotactic Body Radiation Therapy and Intensity-Modulated Radiation Therapy for Prostate Cancer by NCCN Risk Groups}

\author{
Anthony Ricco', Genevieve Manahan ${ }^{1,2}$, Rachelle Lanciano ${ }^{1,2 *}$, Alexandra Hanlon ${ }^{3}$, \\ Jun Yang ${ }^{1,2}$, Stephen Arrigo ${ }^{1}$, John Lamond ${ }^{1,2}$, Jing Feng ${ }^{1}$, Michael Mooreville ${ }^{1}$, \\ Bruce Garber ${ }^{1}$ and Luther Brady ${ }^{1,2}$
}

\footnotetext{
${ }^{1}$ Philadelphia Cyberknife, Delaware County Memorial Hospital, Havertown, PA, USA, ${ }^{2}$ Drexel University College of Medicine, Philadelphia, PA, USA, ${ }^{3}$ University of Pennsylvania, Philadelphia, PA, USA
}

Objectives: The primary objective of this study is to compare freedom from biochemical failure (FFBF) between stereotactic body radiation therapy (SBRT) and intensitymodulated radiation therapy (IMRT) for patients with organ confined prostate cancer treated between 2007 through 2012 utilizing the 2015 National Comprehensive Cancer Network (NCCN) risk stratification guidelines. A secondary objective is to compare our updated toxicity at last follow-up compared with pretreatment with respect to bowel, bladder, sexual functioning, and need for invasive procedures between the two groups.

Methods: We retrospectively reviewed 270 consecutive men treated with either SBRT $(n=150)$ or IMRT $(n=120)$ at a community hospital with two distinct radiation departments and referral patterns. Charts were reviewed for pretreatment and treatment factors including race, age, clinical T stage, initial PSA, Gleason score, use of androgen deprivation therapy, treatment with SBRT vs. IMRT, as well as stratification by 2015 NCCN guidelines. Kaplan-Meier (KM) methodology was used to estimate FFBF, with statistical comparisons accomplished using log rank tests. Multivariable Cox proportional hazard modeling was used to establish independent factors prognostic of biochemical failure. Descriptive statistics were used to describe toxicity graded by a modified Radiation Therapy Oncology Group (RTOG) late radiation morbidity scoring system.

Results: Significant prognostic factors in univariate analysis for FFBF included NCCN risk groups $(p=0.0032)$, grade $(p=0.019)$, and PSA $(p=0.008)$. There was no significant difference in FFBF between SBRT vs. IMRT $(p=0.46)$ with 6-year actuarial FFBF of $91.9 \%$ for SBRT and $88.9 \%$ for IMRT. Multivariable analysis revealed only the NCCN risk stratification to be significant predictor for FFBF $(p=0.04)$. Four-year actuarial FFBF by NCCN risk stratification was 100\% very low risk, 100\% low risk, 96.5\% intermediate risk, $94.5 \%$ high risk, and $72.7 \%$ very high risk. There were no grade 3 gastrointestinal or genitourinary toxicities for either SBRT or IMRT at last follow-up. 


\begin{abstract}
Conclusion: No significant difference in FFBF was found between SBRT and IMRT for organ confined prostate cancer in multivariable analysis within this retrospective data set. Overall toxicity was low. The 2015 NCCN risk stratification was validated in this population and was the only significant factor for FFBF in multivariable analysis.
\end{abstract}

Keywords: IMRT, SBRT, prostate cancer, NCCN guidelines, freedom from biochemical failure, toxicity

\section{INTRODUCTION}

Intensity-modulated radiation therapy (IMRT) has been a standard radiation modality used in the treatment of organ confined prostate cancer. Ten-year actuarial data (median follow-up of 8 years) is available for high dose IMRT up to 81 Gy which demonstrates high efficacy in preventing biochemical failure with acceptable side effect rates (1). Stereotactic body radiation therapy (SBRT) has been accepted as an "appropriate alternative for select patients with low to intermediate risk disease" as per the American Society for Radiation Oncology (ASTRO) policy update of April 2013 and is also supported by the National Comprehensive Cancer Network (NCCN). SBRT publications have validated freedom from biochemical failure (FFBF) and side effect rates comparable to $\operatorname{IMRT}(2,3)$.

The combination of prostate cancer's low alpha/beta ratio, known benefit of dose escalation, and efficacy/safety of high dose rate brachytherapy led to single institutional, multi-institutional, and randomized clinical trials of SBRT for the treatment of prostate cancer $(4,5)$. Despite a clear cost savings for SBRT compared with IMRT in a recent pooled Medicare database analysis, a $7.5 \%$ absolute increased risk of genitourinary (GU) toxicity at 24 months was associated with SBRT (6). To date, the only direct head-to-head comparison between the two modalities with respect to FFBF and toxicity in a single database is from our institution reporting 5-year propensity score analysis with no significant difference between IMRT and SBRT noted (7).

The primary goal of this study is to update FFBF between SBRT and IMRT for men with organ confined prostate cancer treated between 2007 through 2012 utilizing the 2015 NCCN risk stratification guidelines in a larger database from our institution. A secondary objective is to confirm prognostic factors in this larger data base through multivariable analysis. An additional objective is to evaluate toxicity at last follow-up compared with pretreatment with respect to bowel, bladder, sexual functioning, and need for invasive procedures in our updated database with comparisons between IMRT and SBRT.

\section{MATERIALS AND METHODS}

Two hundred seventy consecutive men treated for organ confined prostate cancer using either SBRT $(n=150)$ or IMRT $(n=120)$ between 2007 through 2012 were reviewed on this IRB approved retrospective study. Patients were treated with SBRT at an outpatient radiation facility and IMRT at the community hospital site, both under the same license and radiation department but with distinct geographic and referral patterns. PSA nadir was defined as the lowest PSA value following SBRT or IMRT. Biochemical failure was assessed using the Phoenix Nadir +2 definition (8). Toxicity was assessed using the Radiation Therapy Oncology Group (RTOG) group criteria with modification. If patients required medication for treatment of lower urinary tract symptoms before radiation or at last follow-up, our modification of the RTOG system placed them into grade 2 , which is not required in the RTOG late toxicity scoring system. Erectile function (EF) was graded as grade 0: no issues achieving erection adequate for intercourse, grade 1: erections sufficient for intercourse most of the time but reduced from baseline, grade 2: requiring medications for attainment of EF adequate for intercourse, and grade 3: erections not sufficient for intercourse most of the time despite use of oral medications or can achieve erections with implanted device.

Stereotactic body radiation therapy was delivered using the Cyberknife system with multi-plan inverse treatment planning and motion tracking of internal fiducials. Treatment planning began with transrectal or transperineal ultrasound-guided placement of four gold fiducials into the prostate. A CT scan was obtained 10-14 days later to allow inflammation to subside and ensure fiducials did not migrate. T2 fast echo MRI was obtained and three-dimensionally registered by fiducials to the CT. All patients were simulated in the supine position with immobilization, full bladder, and empty rectum. The clinical target volume (CTV) was the prostate for very low- and low-risk patients, the prostate plus the proximal seminal vesicle for most intermediate, high, and very high-risk patients. Pelvic lymph nodes were never targeted. Five fractions were prescribed to the planning target volume (PTV) that consisted of the CTV with a 5-mm margin in all directions except $3 \mathrm{~mm}$ posteriorly. Dose administered was standard throughout our center, which was based on in-house protocol and clinical trial participation. Initially, our first few patients were treated with 35 Gy (EQD2 = 85, assuming an alpha/beta of 1.5 for prostate cancer), followed by 37.5 Gy (EQD2 $=96.4)$, and at the time of this publication $36.25 \mathrm{~Gy}(\mathrm{EQD} 2=90.6)$, which began 2008 when we participated in a national protocol. The dosimetric goal was to cover at least $95 \%$ of the PTV with the prescribed dose normalized to the $75-85 \%$ isodose line (dose heterogeneity $17-33 \%$ ). Less than $1 \mathrm{~cm}^{3}$ of rectum received $36 \mathrm{~Gy}, 50 \%$ of the prescribed dose could not cross the posterior rectal wall, and $<10 \mathrm{~cm}^{3}$ of bladder received $37 \mathrm{~Gy}$. These dose constraints were utilized for each prostate dose level. The average/median CTV and PTV were $56.7 / 50.1 \mathrm{cc}(\mathrm{SD}=25.7 \mathrm{cc})$ and $97.9 / 89.9 \mathrm{cc}(\mathrm{SD}=37.9 \mathrm{cc})$, respectively. Orthogonal $120-\mathrm{kV}$ X-ray image pairs were obtained throughout treatment for use in motion tracking. The real-time prostate position was locked-on by the relative fiducial position on the X-rays. For those patients with evenly distributed fiducials in the prostate quadrants, the prostate's rotation was also tracked and corrections were made in real time. 
For IMRT, the PTV was defined as the prostate with $8 \mathrm{~mm}$ margin in all directions except $5 \mathrm{~mm}$ posteriorly in very low- and low-risk patients, prostate plus seminal vesicles with $5 / 8 \mathrm{~mm}$ margin for intermediate and some high risk patients, and prostate plus seminal vesicles plus true pelvic lymph nodes with $5 / 8 \mathrm{~mm}$ margin for most high and very high risk patients. Dose constraints to the rectum were defined as V $65<17 \%$ and V $40<35 \%$, while the bladder constraints were V65 $<25 \%$ and V $40<50 \%$. All patients were simulated in the supine position with immobilization, full bladder, and empty rectum. CT and MRI treatment planning was completed with merging of the images for contouring of the prostate. Image guidance was provided by ultrasound pretreatment daily, and patients were treated with full bladder daily. Usually, five to seven isocentric beams were utilized to treat the prostate with $6 \mathrm{MV}$ photons optimized with an inverse optimization algorithm with at least $95 \%$ of the prostate receiving the prescribed dose. Approximately $28 \%$ of men were treated to the prostate alone, $28 \%$ to the prostate + seminal vesicles, and $44 \%$ to the true pelvic lymph nodes + seminal vesicles + prostate. The majority of patients received 75.6 Gy $(\mathrm{EQ} 2=71.3)$ to the prostate in $1.8 \mathrm{~Gy}$ per fraction $(72$ to $<75.6 \mathrm{~Gy}=16.8 \%, 75.6 \mathrm{~Gy}=60.5 \%$, and $>75.6 \mathrm{~Gy}=22.7 \%)$.

Kaplan-Meier (KM) methodology was used to estimate FFBF from end of radiation treatment (EOT), with statistical comparisons accomplished using log rank tests. Simple Cox proportional hazard modeling was used to estimate hazard ratios; multivariable modeling was used to establish independent factors prognostic of biochemical failure among NCCN risk groups and treatment group (IMRT vs. SBRT). Additionally, multivariable modeling was performed using Gleason Score, pretreatment PSA, and treatment group. Separate multivariable models were examined to avoid multicollinearity issues. All analyses were accomplished using SAS V9.4 (Cary, NC).

\section{RESULTS}

\section{Patient and Treatment Characteristics}

The median follow-up time for all patients was 50.2 months (mean = 55.31 , range of 4-108 months). The median follow-up time for SBRT and IMRT patients was 45.53 and 53.38 months, respectively.

Pretreatment and treatment factors are described in Table $\mathbf{1 .}$ Patients were assigned retrospectively by risk groups based on the 2015 NCCN risk stratification guidelines. More patients had PSA $<10$, Gleason score 6 or 7 , and T1c/T2a clinical stage. The median age for IMRT patients was 72 years, whereas the median age for SBRT patients was 67 years. There is a statistically significant difference in distribution of patient and treatment characteristics by radiation treatment group with regard to age, race, $\mathrm{T}$ stage, Gleason score, NCCN risk groups, and use of androgen deprivation therapy (ADT), but not PSA.

Of those patients treated with SBRT, $80 \%$ were treated with either 35 or 36.25 Gy considered the "low dose" group, whereas $20 \%$ were treated with 37.5 Gy considered the "high dose" group. Our previous publication described the effect of higher SBRT dose on outcome and will not be further discussed here (9).
TABLE 1 | Patient descriptive statistics.

\begin{tabular}{|c|c|c|c|c|c|}
\hline Pt characteristics & SBRT & & IMRT & & $p$-Value* \\
\hline Number of Pts. & 150 & & 120 & & \\
\hline Age at diagnosis & Years & & Years & & $<0.0001$ \\
\hline Median (IQR) & $67(11.8)$ & & $72(9.2)$ & & \\
\hline Range & $44-88$ & & $56-89$ & & \\
\hline Pre-tx PSA & $\mathrm{ng} / \mathrm{mL}$ & & $\mathrm{ng} / \mathrm{mL}$ & & 0.1403 \\
\hline Mean (SD) & $8.1(7.8)$ & & $10.8(18.7)$ & & \\
\hline Median (IQR) & $6(3.7)$ & & $6.2(4.5)$ & & \\
\hline Pre-tx PSA & $\begin{array}{l}\text { Number } \\
\text { of Pts. }\end{array}$ & Percent & $\begin{array}{l}\text { Number } \\
\text { of Pts. }\end{array}$ & Percent & 0.2644 \\
\hline$<10 \mathrm{ng} / \mathrm{mL}$ & 122 & 81.0 & 92 & 76.7 & \\
\hline $10-20$ ng/mL & 19 & 13.0 & 14 & 11.7 & \\
\hline$>20 \mathrm{ng} / \mathrm{mL}$ & 9 & 6.0 & 14 & 11.7 & \\
\hline T-stage & $\begin{array}{l}\text { Number } \\
\text { of Pts. }\end{array}$ & Percent & $\begin{array}{l}\text { Number } \\
\text { of Pts. }\end{array}$ & Percent & $<0.0001$ \\
\hline T1c & 113 & 75.3 & 43 & 35.8 & \\
\hline $\mathrm{T} 2 \mathrm{a}$ & 20 & 13.3 & 22 & 18.3 & \\
\hline$>\mathrm{T} 2 \mathrm{a}$ & 17 & 11.3 & 55 & 45.8 & \\
\hline Gleason score & $\begin{array}{l}\text { Number } \\
\text { of Pts. }\end{array}$ & Percent & $\begin{array}{l}\text { Number } \\
\text { of Pts. }\end{array}$ & Percent & $<0.0001$ \\
\hline $5-6$ & 83 & 55.3 & 34 & 28.3 & \\
\hline 7 & 55 & 36.7 & 61 & 50.8 & \\
\hline $8+$ & 12 & 8.0 & 25 & 20.8 & \\
\hline $\begin{array}{l}\text { NCCN } 2015 \text { risk } \\
\text { group }\end{array}$ & $\begin{array}{l}\text { Number } \\
\text { of Pts. }\end{array}$ & Percent & $\begin{array}{l}\text { Number } \\
\text { of Pts. }\end{array}$ & Percent & $<0.0001$ \\
\hline Very low & 33 & 22.0 & 9 & 7.5 & \\
\hline Low & 34 & 22.7 & 13 & 10.8 & \\
\hline Intermediate & 51 & 34.0 & 38 & 31.7 & \\
\hline High & 25 & 16.7 & 48 & 40.0 & \\
\hline Very high & 7 & 4.6 & 12 & 10.0 & \\
\hline Race $N=145$ & $\begin{array}{l}\text { Number } \\
\text { of Pts. }\end{array}$ & Percent & $\begin{array}{l}\text { Number } \\
\text { of Pts. }\end{array}$ & Percent & $<0.0001$ \\
\hline African-American & 49 & 32.7 & 17 & 14.2 & \\
\hline Caucasian & 90 & 60.0 & 101 & 84.2 & \\
\hline Other & 7 & 4.7 & 1 & 0.8 & \\
\hline Unknown & 4 & 2.7 & 1 & 0.8 & \\
\hline $\begin{array}{l}\text { Hormone } \\
\text { treatment }\end{array}$ & $\begin{array}{l}\text { Number } \\
\text { of Pts. }\end{array}$ & Percent & $\begin{array}{l}\text { Number } \\
\text { of Pts. }\end{array}$ & Percent & $<0.0001$ \\
\hline noADT & 109 & 73 & 34 & 28 & \\
\hline ADT & 41 & 27 & 86 & 72 & \\
\hline
\end{tabular}

${ }^{*}$ Continuous variable $p$-value computed by $t$-test. Categorical variable $p$-value computed by fisher exact test.

\section{PSA and Biochemical Control}

Significant prognostic factors in univariate analysis for FFBF included initial PSA $(p=0.008)$, NCCN risk groups $(p=0.003)$, and Gleason score $(p=0.02)$ (Figures 1-3). No significant differences in FFBF were observed by age, T-stage, race or use of androgen deprivation.

Four-year actuarial FFBF by NCCN risk stratification was $100 \%$ very low risk, $100 \%$ low risk, $96.5 \%$ intermediate risk, 94.5\% high risk, and $72.7 \%$ very high risk. ${ }^{1}$ Four-year actuarial FFBF rates were $96.7 \%$ for PSA $<10,100 \%$ for PSA $10-20$ and $77.9 \%$ for PSA $>20$. Five-year actuarial FFBF rates stratified by

${ }^{1}$ Only eight patients at risk with very high risk prostate cancer at 4 years. 


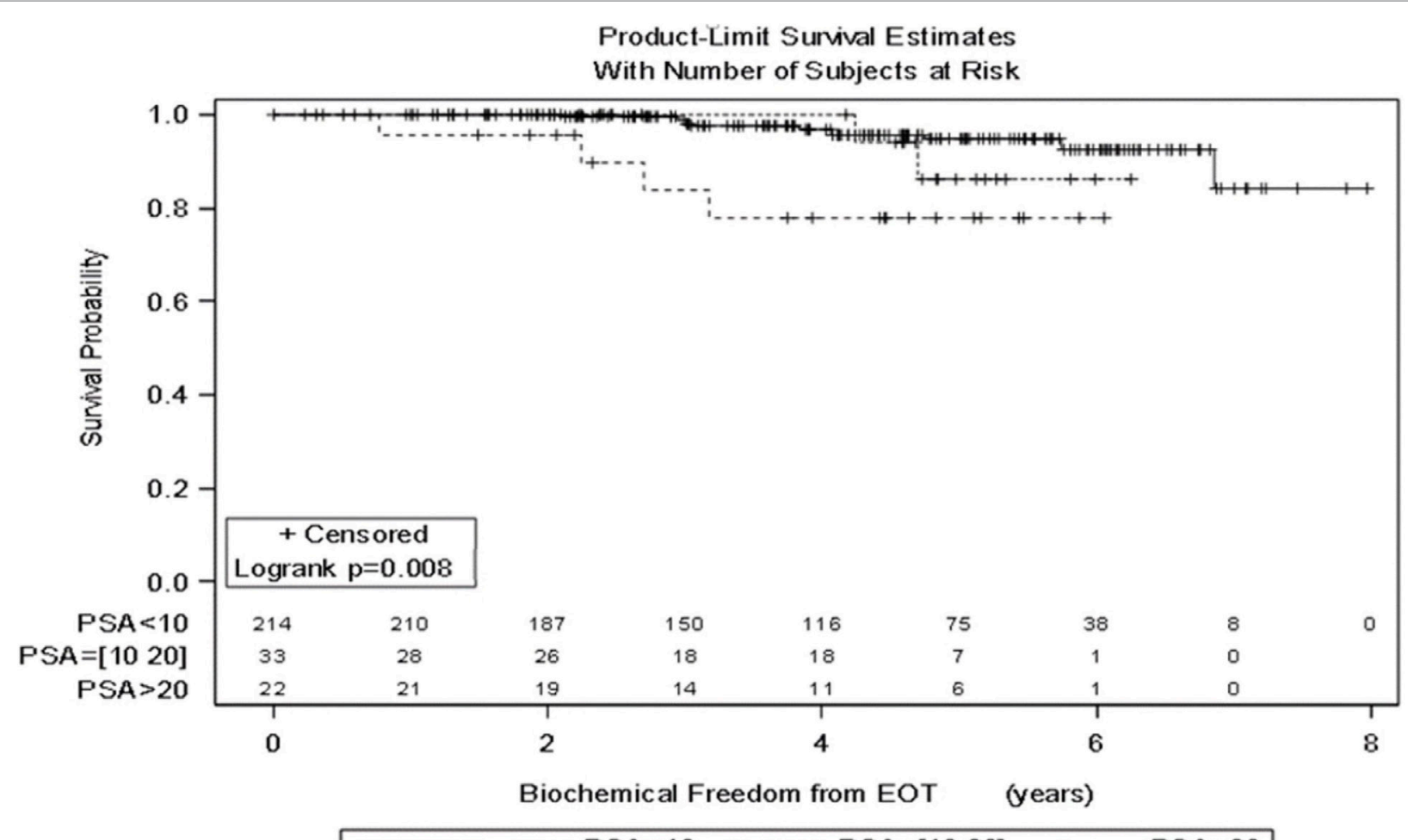

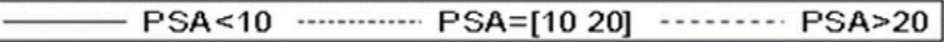

FIGURE 1 | KM curve stratifying FFBF by Initial PSA.

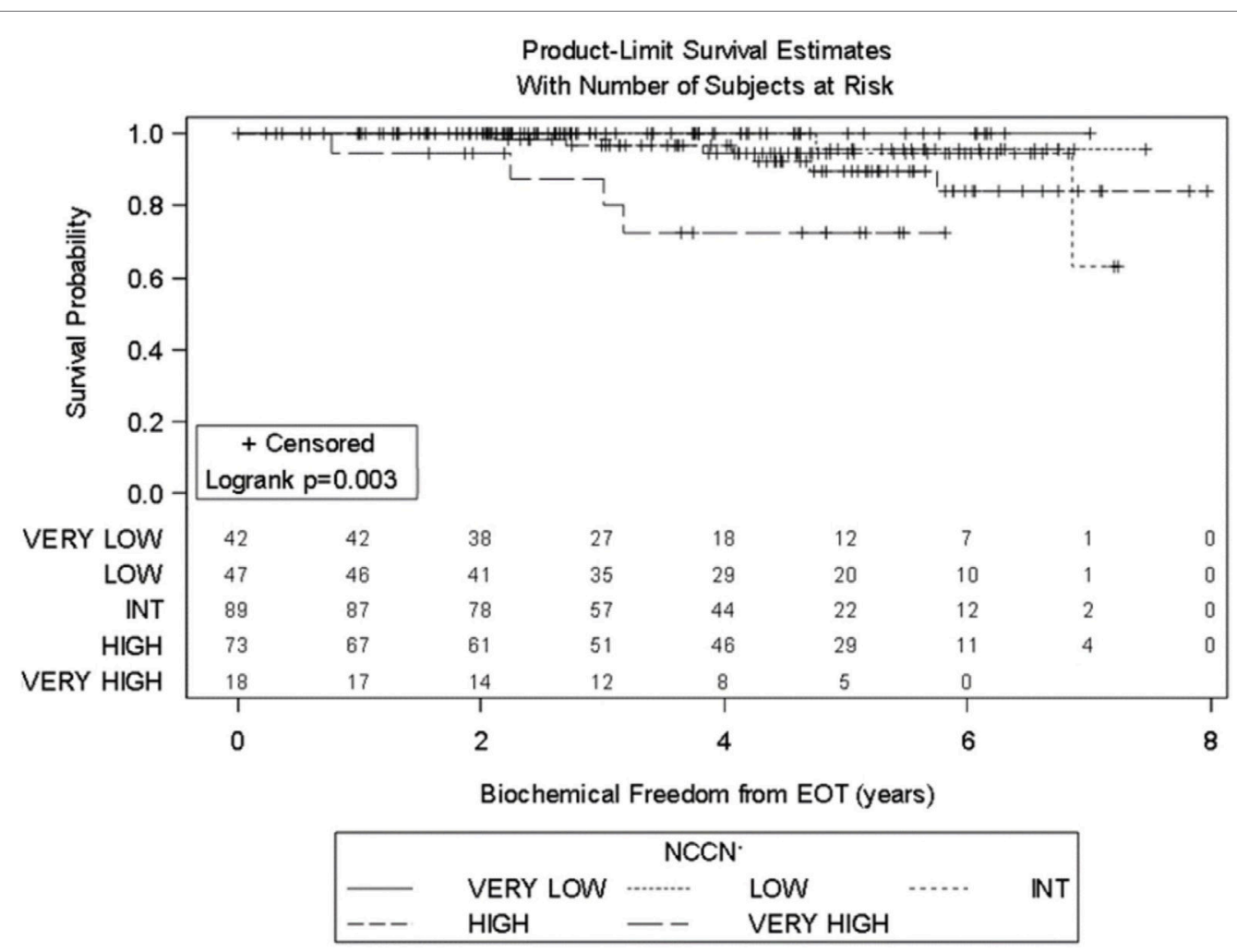

FIGURE 2 | KM curve stratifying FFBF by 2015 NCCN Guidelines. 


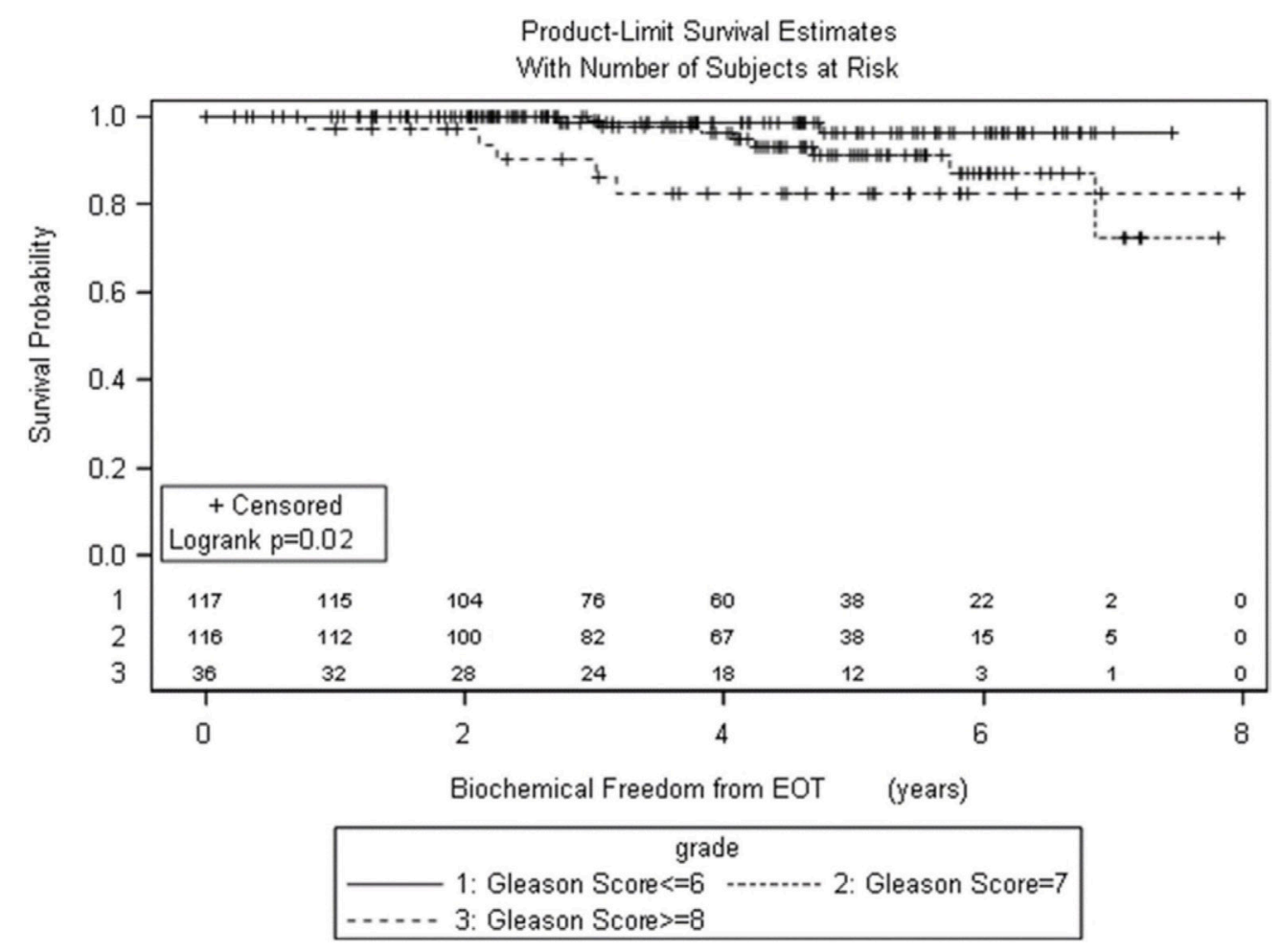

FIGURE $3 \mid$ KM curve stratifying FFBF by Gleason score

Gleason score were GS $\leq 696.5 \%$, GS $=791.1 \%$, and GS $\geq 8$ 82.4\%. Six-year actuarial FFBF was $91.9 \%$ for the SBRT group and $88.9 \%$ for the IMRT group with no significant difference in univariate analysis ( $p=0.46$ ) (Figure 4; Table 2).

Seven patients treated with SBRT experienced biochemical failure, one in the low-risk group, two each in the intermediate, high, and very high-risk groups, all from the low dose category. Nine patients treated with IMRT experienced biochemical failure, two in the intermediate-risk group, four in the high-risk group, and three in the very-high risk groups.

Initial multivariable analysis included the NCCN risk groups as well as radiation treatment modality (IMRT vs. SBRT). Because Gleason score and PSA are a component of the NCCN risk groups, a second multivariable analysis included only Gleason score, PSA, and radiation treatment modality to avoid inappropriate weighing of prognostic factors. Only NCCN risk stratification was a significant predictor for FFBR in multivariable analysis $(p=0.04)$.

\section{Toxicity}

Five patients (3.3\%) experienced acute grade $3 \mathrm{GU}$ toxicities that resolved to either grade 1 or grade 2 by last follow-up in the SBRT group. Three of the five patients required TURP for resolution of acute symptoms, all three received $37.5 \mathrm{~Gy}$.

For the SBRT group at most recent follow-up, GU toxicities were grade 2 in $16 \%$ compared with $20 \%$ grade 2 at baseline before treatment. Of the $16 \%$ grade 2 patients at last follow-up, 18/24 were graded as such purely due to a requirement for medication for lower urinary tract symptoms. Of the remaining six patients, three had mild hematuria with one patient on warfarin and one patient on finasteride. Two patients had incontinence, and one patient required self-catheterization. There were no late grade 3 GU toxicities following SBRT at most recent follow-up (Table 2; Figure 5).

For the SBRT group at most recent follow-up, gastrointestinal (GI) toxicities were grade 2 in $2.7 \%$ compared with $1.3 \%$ grade 2 at baseline before treatment. No late grade 3 GI toxicity was reported following SBRT.

For the SBRT group at most recent follow-up, EF was grade 2 (requiring medication for adequate EF) in 35\%, compared with $18.7 \%$ at baseline before treatment. Six percent of men at most recent follow-up had EF inadequate for intercourse despite medication or required penile prosthesis (grade 3) compared with $1.3 \%$ grade 3 at baseline before treatment. Ninety-seven percent of men with $\mathrm{EF}$ adequate for intercourse at presentation without medications (grades $0-1$ ) were still potent either with or without medication at last follow-up (grades 0-2) (Table 3; Figure 6).

For the IMRT group at most recent follow-up, GU toxicities were grade 2 in $23 \%$ compared with $26 \%$ grade 2 at baseline before treatment. Of the $23 \%$ grade 2 patients at last follow-up, 20/27 were graded as such purely due to a requirement for medication for lower urinary tract symptoms. Of the seven remaining IMRT patients with grade 2 toxicity, both hematuria cases were confounded with use of anticoagulant, with five other grade 2 toxicity cases requiring cystoscopy or other forms of invasive diagnostic studies. There were no late grade $3 \mathrm{GU}$ toxicities following IMRT, 


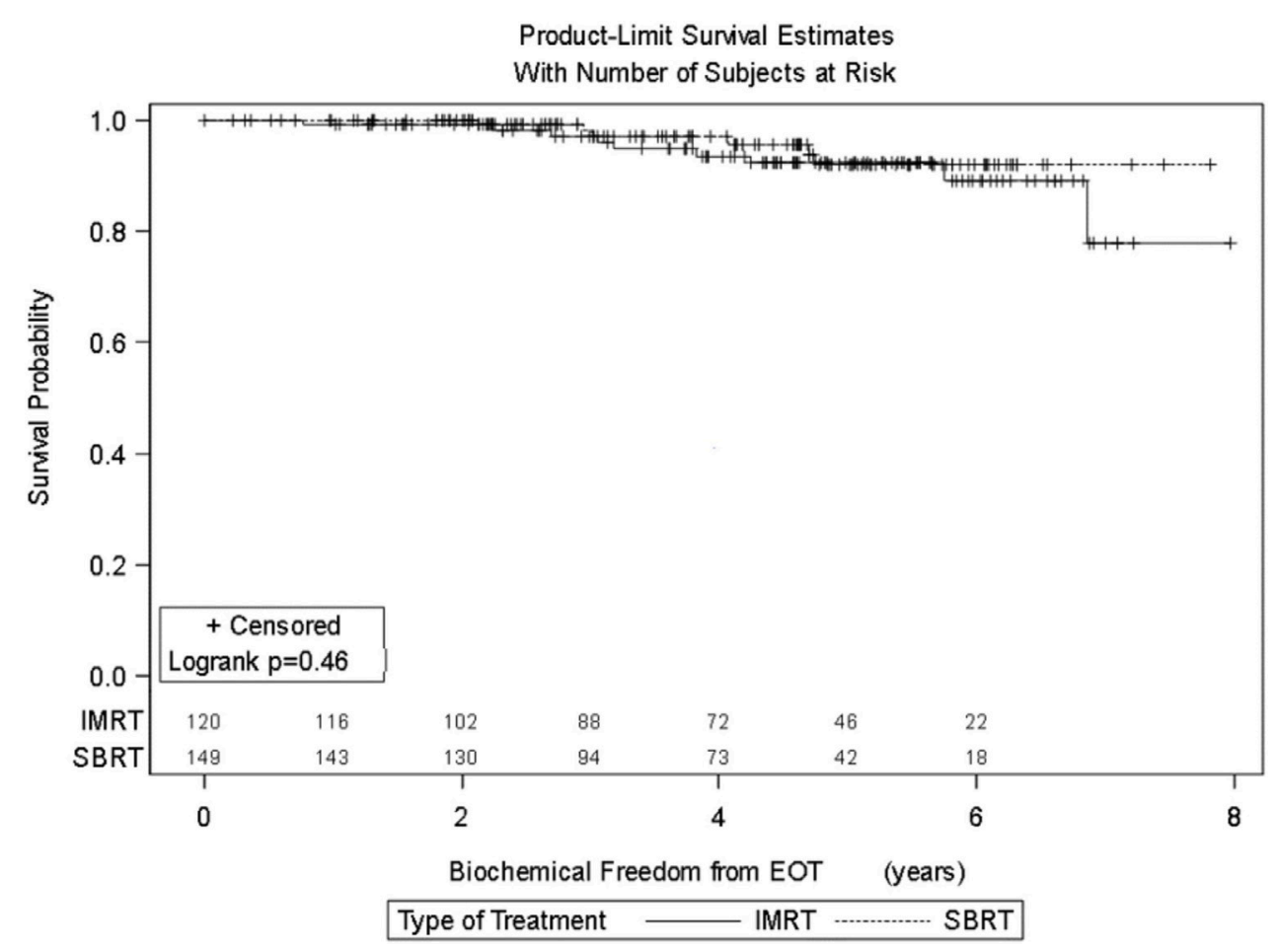

FIGURE 4 | KM curve stratifying FFBF by treatment type (IMRT vs. SBRT)

TABLE 2 | Univariate analysis of FFBF by multiple variables.

\begin{tabular}{|c|c|c|c|c|c|c|c|}
\hline & & $\begin{array}{c}\text { 1-year } \\
(\%)\end{array}$ & $\begin{array}{c}\text { 2-year } \\
(\%)\end{array}$ & $\begin{array}{c}\text { 3-year } \\
(\%)\end{array}$ & $\begin{array}{c}\text { 4-year } \\
(\%)\end{array}$ & $\begin{array}{c}\text { 5-year } \\
(\%)\end{array}$ & $p$-Value \\
\hline All patients & $n=270$ & 99.6 & 99.6 & 97.7 & 95.4 & 92.2 & \\
\hline Age & $\begin{array}{l}\leq 69^{a} \\
>69^{a}\end{array}$ & $\begin{array}{r}99.3 \\
100.0\end{array}$ & $\begin{array}{r}99.3 \\
100.0\end{array}$ & $\begin{array}{r}95.5 \\
100.0\end{array}$ & $\begin{array}{l}94.5 \\
96.4\end{array}$ & $\begin{array}{l}93.2 \\
91.2\end{array}$ & 0.8337 \\
\hline Treatment & $\begin{array}{l}\text { SBRT } \\
\text { IMRT }\end{array}$ & $\begin{array}{r}100.0 \\
99.2\end{array}$ & $\begin{array}{r}100.0 \\
99.2\end{array}$ & $\begin{array}{l}98.2 \\
97.1\end{array}$ & $\begin{array}{l}97.1 \\
93.6\end{array}$ & $\begin{array}{l}92.0 \\
92.2\end{array}$ & 0.4608 \\
\hline Risk group & $\begin{array}{l}\text { Very low } \\
\text { Low } \\
\text { Int. } \\
\text { High } \\
\text { Very high }\end{array}$ & $\begin{array}{r}100.0 \\
100.0 \\
100.0 \\
100.0 \\
94.4\end{array}$ & $\begin{array}{r}100.0 \\
100.0 \\
100.0 \\
100.0 \\
94.4\end{array}$ & $\begin{array}{r}100.0 \\
100.0 \\
98.3 \\
96.5 \\
87.2\end{array}$ & $\begin{array}{r}100.0 \\
100.0 \\
96.5 \\
94.5 \\
72.7\end{array}$ & $\begin{array}{r}100.0 \\
95.7 \\
94.2 \\
89.7 \\
72.7\end{array}$ & 0.0032 \\
\hline Pre-tx PSA & $\begin{array}{l}<10 \\
10-20 \\
>20\end{array}$ & $\begin{array}{r}100.0 \\
100.0 \\
95.5\end{array}$ & $\begin{array}{r}100.0 \\
100.0 \\
95.5\end{array}$ & $\begin{array}{r}98.8 \\
100.0 \\
83.9\end{array}$ & $\begin{array}{r}96.7 \\
100.0 \\
77.9\end{array}$ & $\begin{array}{l}94.6 \\
86.3 \\
77.9\end{array}$ & 0.0083 \\
\hline T-stage & $\begin{array}{l}\mathrm{T} 1 \mathrm{c} / \mathrm{T} 2 \mathrm{a} \\
\mathrm{T} 2 \mathrm{~B} / \mathrm{T} 2 \mathrm{C} \\
\mathrm{T} 3 \mathrm{a}\end{array}$ & $\begin{array}{r}100.0 \\
100.0 \\
83.3\end{array}$ & $\begin{array}{r}100.0 \\
100.0 \\
83.3\end{array}$ & $\begin{array}{l}99.3 \\
94.4 \\
83.3\end{array}$ & $\begin{array}{l}97.0 \\
92.2 \\
83.3\end{array}$ & $\begin{array}{c}93.0 \\
89.8 \\
.\end{array}$ & 0.1184 \\
\hline $\begin{array}{l}\text { Gleason } \\
\text { score }\end{array}$ & $\begin{array}{l}5-6 \\
7 \\
8+\end{array}$ & $\begin{array}{r}100.0 \\
100.0 \\
97.1\end{array}$ & $\begin{array}{r}100.0 \\
100.0 \\
97.1\end{array}$ & $\begin{array}{l}98.8 \\
98.8 \\
90.1\end{array}$ & $\begin{array}{l}98.8 \\
96.2 \\
82.4\end{array}$ & $\begin{array}{l}96.5 \\
91.1 \\
82.4\end{array}$ & 0.0199 \\
\hline ADT & $\begin{array}{l}\text { No ADT } \\
\text { ADT }\end{array}$ & $\begin{array}{r}100.0 \\
99.2\end{array}$ & $\begin{array}{r}100.0 \\
99.2\end{array}$ & $\begin{array}{l}98.1 \\
97.2\end{array}$ & $\begin{array}{l}98.1 \\
92.8\end{array}$ & $\begin{array}{l}92.4 \\
91.4\end{array}$ & 0.2394 \\
\hline
\end{tabular}

${ }^{a}$ Median.

which improved from $4.2 \%$ at baseline before treatment (Table 3; Figure 5).

For the IMRT group at most recent follow-up, GI toxicities were grade 2 in $2.5 \%$ compared with $1.7 \%$ grade 2 at baseline

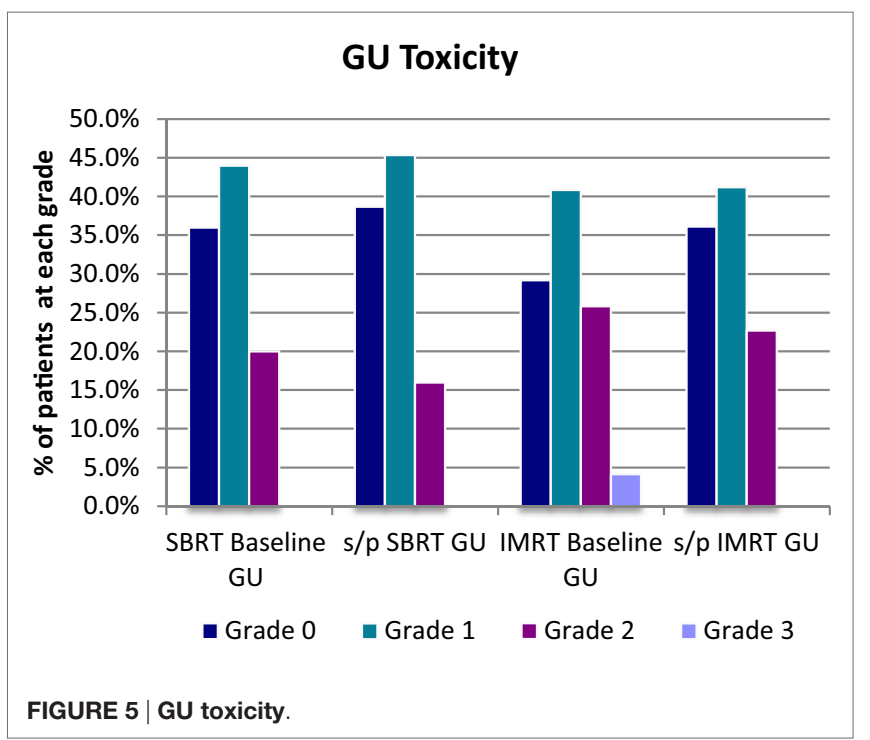

before treatment. No late grade 3 GI toxicities were reported following IMRT.

For the IMRT group at most recent follow-up, EF was grade 2 (requiring medication for adequate EF) in 14\%, compared with $12 \%$ at baseline before treatment. Sixty-eight percent of men at most recent follow-up had EF inadequate for intercourse despite medication or required penile prosthesis (grade 3) compared with $58 \%$ grade 3 at baseline before treatment. Approximately $85.7 \%$ of men with $\mathrm{EF}$ adequate for intercourse at presentation without 
TABLE 3 | Baseline profiles (GU, GI, and EF) for SBRT and IMRT and toxicity profile at last FU.

\begin{tabular}{|c|c|c|c|c|}
\hline $\begin{array}{l}\text { GU } \\
\text { Grade }\end{array}$ & $\begin{array}{c}\text { SBRT } n=150 \\
\text { SBRT baseline GU }\end{array}$ & $\begin{array}{c}n=150 \\
\text { s/p SBRT GU }\end{array}$ & $\begin{array}{c}\text { IMRT } n=120 \\
\text { IMRT baseline GU }\end{array}$ & $\begin{array}{c}n=119 \\
\text { s/p IMRT GU }\end{array}$ \\
\hline 0 & $36.0 \%$ & $38.7 \%$ & $29.2 \%$ & $36.1 \%$ \\
\hline 1 & $44.0 \%$ & $45.3 \%$ & $40.8 \%$ & $41.2 \%$ \\
\hline 2 & $20.0 \%$ & $16.0 \%$ & $25.8 \%$ & $22.7 \%$ \\
\hline 3 & $0.0 \%$ & $0.0 \%$ & $4.2 \%$ & $0.0 \%$ \\
\hline$n=$ & 150 & 150 & 120 & 119 \\
\hline $\begin{array}{l}\text { GI } \\
\text { Grade }\end{array}$ & $\begin{array}{c}\text { SBRT } n=150 \\
\text { SBRT baseline GI }\end{array}$ & $\begin{array}{c}n=150 \\
\text { s/p SBRT GI }\end{array}$ & $\begin{array}{l}\text { IMRT } n=120 \\
\text { IMRT baseline GI }\end{array}$ & $\begin{array}{c}n=119 \\
\text { s/p IMRT GI }\end{array}$ \\
\hline 0 & $87.3 \%$ & $88.7 \%$ & $93.3 \%$ & $90.8 \%$ \\
\hline 1 & $11.3 \%$ & $8.7 \%$ & $5.0 \%$ & $6.7 \%$ \\
\hline 2 & $1.3 \%$ & $2.7 \%$ & $1.7 \%$ & $2.5 \%$ \\
\hline 3 & $0.0 \%$ & $0.0 \%$ & $0.0 \%$ & $0.0 \%$ \\
\hline$n=$ & 150 & 150 & 120 & 119 \\
\hline $\begin{array}{l}\text { EF } \\
\text { Grade }\end{array}$ & $\begin{array}{c}\text { SBRT } n=150 \\
\text { SBRT baseline EF }\end{array}$ & $\begin{array}{c}n=150 \\
\text { s/p SBRT EF }\end{array}$ & $\begin{array}{c}\text { IMRT } n=117 \\
\text { IMRT baseline EF }\end{array}$ & $\begin{array}{c}n=111 \\
\text { s/p IMRT EF }\end{array}$ \\
\hline 0 & $49.3 \%$ & $34.0 \%$ & $17.9 \%$ & $11.7 \%$ \\
\hline 1 & $30.7 \%$ & $24.7 \%$ & $12.0 \%$ & $7.2 \%$ \\
\hline 2 & $18.7 \%$ & $35.3 \%$ & $12.0 \%$ & $13.5 \%$ \\
\hline 3 & $1.3 \%$ & $6.0 \%$ & $58.1 \%$ & $67.6 \%$ \\
\hline$n=$ & 150 & 150 & 117 & 111 \\
\hline
\end{tabular}

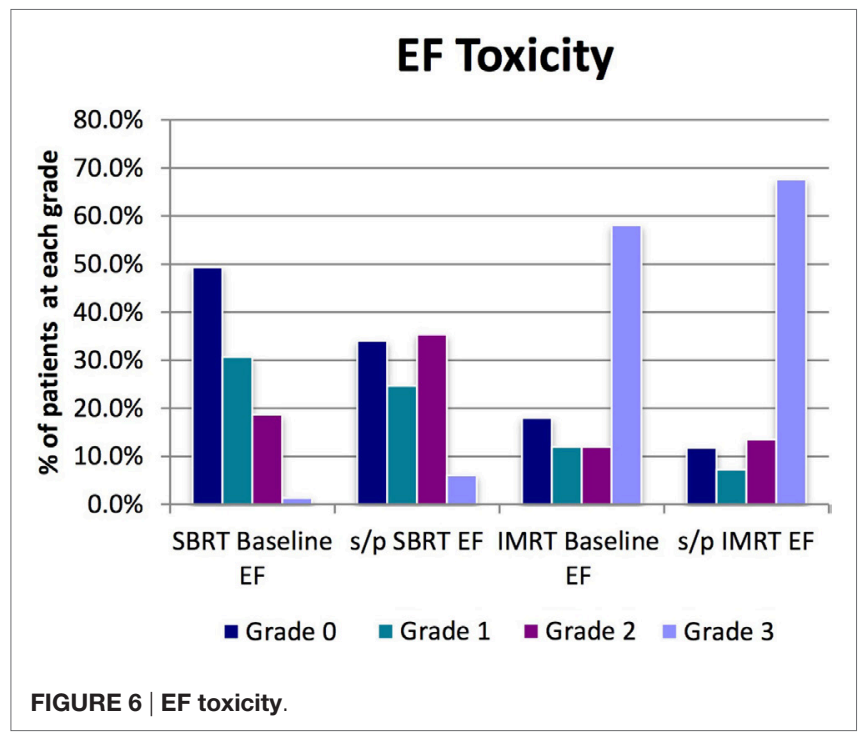

medications were still potent either with or without medication at last follow-up (Table 3; Figure 6).

\section{DISCUSSION}

Our study provides an updated comparison of FFBF and toxicity of SBRT and IMRT for the treatment of localized prostate cancer. To date, one other study has made this comparison, only reporting acute/chronic toxicity and cost comparisons between the two modalities in a national database (6). Our study offers late toxicity in addition to estimating FFBF with median follow-up times approaching 5 years. We also provided FFBF stratified by the 2015 NCCN guidelines of five risk groups which is lacking in the literature and the only factor significant in multivariate analysis for our study. We explored various known pretreatment factors in univariate analysis with other exploratory pretreatment factors such as race and age which we had not reported in our previous published experience $(7,9)$. We also explored use of hormone therapy as a confounding treatment variable in addition to fractionation scheme.

Intensity-modulated radiation therapy continues to be a standard radiotherapeutic technique for the definitive treatment of localized prostate cancer using a conventionally fractionated approach with 1.8-2.0 Gy fractions 5 days/week over 8-9 weeks. A decade of data supports this fractionation scheme for localized prostate cancer, with excellent biochemical control, overall survival, and acceptable toxicity (1). Phase 3 clinical trials of IMRT suggested that this new technology provided non-inferior control with acceptable acute toxicity, based on the rationale that IMRT was an innovation in targeting but prescription dose was based on an already proven fractionation scheme $(10,11)$. Because of an improved therapeutic ratio, dose escalation trials could be done with improved outcome $(1,12-15)$. Michalski et al. in 2013 reported the first randomized data showing a decrease in grade 2 and above GI toxicity from $22 \%$ with 3D-CRT to $15.1 \%$ with IMRT in the $79.2 \mathrm{~Gy}$ arm of RTOG 0126 ( $p=0.04)$. In addition, although not statistically significant, grade 3 and above toxicity was reduced from 5 to $2.6 \%$ with IMRT (16). Updated analysis of this trial showed a decrease in biochemical failure, distant metastases with high dose 79.2 Gy compared with $70.2 \mathrm{~Gy}$; however, no increase in survival was noted at 10 years with higher time to late grade 3 or greater GI toxicty for the $79.2 \mathrm{~Gy}$ arm (17).

While we await results from an ongoing Swedish phase 3 trial of hypofractionated radiotherapy delivered in $>5$ fractions completed June 2015, there have been four reported phase 3 clinical trials of hypofractionation in $>5$ fractions compared with conventionally fractionated radiation which show no clinically significant difference in rates of efficacy and late toxicity, with median follow-up from 51 to 90 months (18-22). A recent noninferiority-designed randomized controlled trial concluded no difference in efficacy with minimal increase in toxicity with a moderate hypofractionated regimen (23).

We also await the results of RTOG 0938, an equivalency study of low-risk prostate cancer, randomizing extreme hypofractionation with $36.25 \mathrm{~Gy}$ in 5 fractions compared with moderate hypofractionation of $51.6 \mathrm{~Gy}$ in 12 fractions. The study was closed February 2014 with 255 patients accrued with the primary objective of equivalence of 1-year health-related quality of life (24). No difference in 1-year quality of life or toxicity was recently reported in abstract form of this trial (5).

Several recent SBRT publications report non-inferior clinical efficacy with minimal toxicity. King et al. reported a prospective study including 1100 patients from 8 institutions which included 135 patients with at least 5-year follow-up. Among these 135, biochemical relapse-free survival rates were 99 and $93 \%$ for low- and intermediate-risk, with toxicity rates comparable to IMRT (4). While clinicians would like to see 10-year follow-up prospective randomized clinical trials to assess the efficacy of SBRT in the treatment of localized prostate cancer, the studies of SBRT that are available show encouraging results with follow-up approaching the single institutional trials of IMRT (1). Single institutions and pooled institutions or registries have shown efficacy and acute toxicity on par with IMRT $(2-4,25-27)$. A recent abstract 
by Katz reports the longest follow-up and outcome for a group of 515 men with organ confined prostate cancer stratified by three risk groups. With a median follow-up (FU) of 84 months, 9-year FFBF of $95 \%$ low risk, $89 \%$ intermediate risk, and $66 \%$ high risk groups was reported with $1.9 \%$ RTOG grade 3 urinary toxicity but no grade 3 GI toxicity (28).

With the 2015 NCCN risk stratification, multiple risk factors (which include Gleason score, pretreatment PSA, and clinical stage) promote stage migration and more homogeneity within groups. There were no biochemical failures for the very low-risk group within either SBRT or IMRT questioning the need for treatment in this very low-risk group. While biochemical failure was experienced in each other NCCN subgroup, the high and very high groups were the most at risk. Of interest is that despite no adjuvant lymph node treatment in the SBRT group, there was no significant difference in FFBR between SBRT or IMRT consistent with Lawton et al. and Amini et al. for high risk prostate cancer patients where no survival difference was noted between men treated with whole pelvis vs. prostate only conventionally fractionated external beam radiation $(29,30)$.

Stereotactic body radiation therapy seems well suited for prostate cancer for a number of reasons. The combination of prostate cancer's low $a / b$ ratio, demonstrated benefit of dose escalation above conventional doses, and efficacy/safety of high dose rate brachytherapy hypofractionation would lead one to believe SBRT should be at least comparable to IMRT in efficacy and toxicity for the treatment of prostate cancer. SBRT also has sparked interest due its convenience (duration of 1-2 weeks as compared with 8-9 weeks of IMRT treatment), non-invasive nature of treatment (compared with brachytherapy), and lower cost. Yu et al. recently published a study looking at Medicare records between patients treated with SBRT and IMRT and found that the mean treatment cost was $\$ 13,645$ for SBRT vs. $\$ 21,023$ for IMRT, at a time of increasing cost conscientiousness in the US (6).

Despite the fact all men were treated in a single hospital system within one radiation department, patients treated with SBRT and IMRT came from distinct treatment facilities with only one radiation platform available at each site with separate referral patterns. Low-risk patients were not preferentially selected for SBRT (Table 1). SBRT patients came from five different states, many self-referred and motivated for treatment with SBRT. IMRT patients alternatively came from the region surrounding the community hospital. Two physicians treated all patients with IMRT, while the majority of SBRT patients were treated by four physicians with only one physician treating at both sites. We began a prostate IMRT program in 2003 with significant experience by 2007 when this study began. Alternatively, we began an SBRT program in 2007 with early learning curve and more variation in treatment regimens in the early years. Of our SBRT patients who developed the most severe acute GU toxicity all were from the earliest era with higher doses and less experience. A recent dose escalation trial for prostate cancer treated with SBRT showed acceptable toxicities up to 47.5 Gy over 2.5 weeks (31). Our low toxicity in both the SBRT and IMRT groups suggest that there may be room for dose escalation with our series as well.

A commonly cited reason preventing widespread use of SBRT in localized prostate cancer is that adoption should not happen until we have results from randomized controlled phase 3 trials, due to fears of late toxicity. Yu et al. recently brought this issue to the forefront, with a comparison of SBRT to IMRT using Medicare beneficiary data on patients treated from 2008 to 2011. This study showed an increase in early and late GU toxicity with SBRT as compared with IMRT, with the respective increase at 6,12 , and 24 months in the rates of GU toxicity of $3 \%$ ( 15.6 vs. $12.6 \%$ ), $3.9 \%$ (27.1 vs. $23.2 \%$ ), and $7.6 \%$ ( 43.9 vs. $36.3 \%$ ) (6). In contrast to the Yu study, we were able to assess baseline GU function and GU function status post SBRT and IMRT, in addition to grading the severity of GU toxicity. We found no difference between SBRT and IMRT in grade 2 GI and GU toxicity and no grade 3 toxicity after treatment in either group at most recent follow-up. Because we coded toxicity at last follow-up, the cumulative risk may be underestimated for patients with limited follow-up.

The limitations of this study include fewer high and very high risk men treated with SBRT and IMRT compared with the larger groups of very low-, low-, and intermediate-risk patients and limited power for multivariable assessment given the sample size and number of events. Another limitation is the uneven distribution in use of ADT between radiation treatment groups which could affect FFBF in particular for high and very high risk patients. Our treatment groups were unbalanced with regard to prognostic factors significant in univariate analysis such as Gleason Score and NCCN risk group. In multivariable analysis, however, only NCCN risk group was significant for FFBF but treatment group (IMRT or SBRT) was not significant in univariate or multivariable analysis. It is possible that there are additional factors not accounted for which may affect these results which is inherent in all retrospective analyses.

We did not routinely perform quality of life measurements prior to initiation of radiation with either IMRT or SBRT; however, we are now routinely obtaining Expanded Prostate Cancer Index Composite (EPIC), International Prostate Symptom Score (I-PSS), Bowel Health Inventory, and Sexual Health Inventory for Men (SHIM) in follow-up. Using patient-reported outcomes for RTOG 0126 trial, no difference was noted for the 79.2 Gy dose level between IMRT and 3-dimensional conformal radiation therapy through 24 months for bladder, bowel or erectile function. This study highlights the importance of patient reported outcomes as well as toxicity scales such as reported by the RTOG (32). The strength of this study is the uniform treatment for both IMRT and SBRT in a single hospital department with very separate referral patterns which limited treatment selection bias analyzed by known prognostic factors including stratification by NCCN 2015 guidelines.

In our experience, SBRT is an alternative to IMRT in the treatment of localized prostate cancer, with no significant difference between SBRT and IMRT for FFBF found. In this study, we validated the use of the 2015 NCCN guidelines for prostate cancer and have provided FFBF estimates using the five risk strata. To the best of our knowledge, no previous database describing outcome for prostate cancer following radiation has validated the NCCN risk strata, which is the only prognostic factor significant in multivariable analysis. Comparative effectiveness data are lacking for IMRT vs. SBRT for prostate cancer. Our paper contributes to 
this literature, which is hypothesis generating but awaits direct comparison in a randomized trial.

\section{AUTHOR CONTRIBUTIONS}

$\mathrm{RL}$ - treated patients in review, conceived project, data management, statistical review and analysis, manuscript preparation, review, and submission. AR - data management, statistical review and analysis, manuscript preparation, review and submission. GM - data management, analysis, statistics, and review of manuscript. AH - statistical analysis, manuscript preparation, and review. LB - treated patients in review, manuscript preparation,

\section{REFERENCES}

1. Alicikus ZA, Yamada Y, Zhang Z, Pei X, Hunt M, Kollmeier M, et al. Tenyear outcomes of high-dose, intensity-modulated radiotherapy for localized prostate cancer. Cancer (2011) 117:1429-37. doi:10.1002/cncr.25467

2. Katz AJ, Kang J. Stereotactic body radiotherapy as treatment for organ confined low and intermediate risk prostate carcinoma, an eight year study. Radiat Oncol (2014) 4:1-6. doi:10.1186/1748-717X-9-1

3. King CR, Collins S, Fuller D, Wang PC, Kupelian P, Steinberg M, et al. Health-related quality of life after stereotactic body radiation therapy for localized prostate cancer: results from a multi-institutional consortium of prospective trials. Int J Radiat Oncol Biol Phys (2013) 87:939-45. doi:10.1016/j.jirobp.2013.08.019

4. King CR, Freeman D, Kaplan I, Fuller D, Bolzicco G, Collins S, et al. Stereotactic body radiotherapy for localized prostate cancer: pooled analysis from a multi-institutional consortium of prospective phase II trials. Radiother Oncol (2013) 109:217-21. doi:10.1016/j.radonc.2013.08.030

5. Lukka H, Stephanie P, Bruner D, Bahary JP, Lawton CAF, Efstathiou JA, et al. Patient-reported outcomes in NRG oncology/RTOG 0938, a randomized phase 2 study evaluating 2 ultrahypofractionated regimens (UHRs) for prostate cancer. Int J Radiat Oncol Biol Phys (2016) 94:2. doi:10.1016/j. ijrobp.2015.10.046

6. Yu JB, Cramer LD, Herrin J, Soulos PR, Potosky AL, Gross CP, et al. Stereotactic body radiation therapy versus intensity-modulated radiation therapy for prostate cancer: comparison of toxicity. J Clin Oncol (2014) 32(12):1195-201. doi:10.1200/JCO.2013.53.8652

7. Oliai C, Bernetich M, Brady L, Yang J, Hanlon A, Lamond J, et al. Propensity score matched comparison of SBRT versus IMRT for the treatment of localized prostate cancer. J Radiat Oncol (2016) 5:187-95. doi:10.1007/ s13566-015-0237-0

8. Thames H, Kuban D, Levy L, Horwitz EM, Kupelian P, Martinez A, et al. Comparison of alternative biochemical failure definitions based on clinical outcome in 4839 prostate cancer patients treated by external beam radiotherapy between 1986 and 1995. Int J Radiat Oncol Biol Phys (2003) 57:929-43. doi:10.1016/S0360-3016(03)00631-X

9. Bernetich M, Oliai C, Lanciano R, Hanlon A, Lamond J, Arrigo S, et al. SBRT for the primary treatment of localized prostate cancer: the effect of Gleason score, dose and heterogeneity of intermediate risk on outcome utilizing 2.2014 NCCN risk stratification guidelines. Front Oncol (2014) 4:312. doi:10.3389/ fonc. 2014.00312

10. Sheets NC, Goldin GH, Meyer AM, Wu Y, Chang Y, Stürmer T, et al. Intensitymodulated radiation therapy, proton therapy, or conformal radiation therapy and morbidity and disease control in localized prostate cancer. JAMA (2012) 307:1611-20. doi:10.1001/jama.2012.460

11. Nguyen PL, Gu X, Lipsitz SR, Choueiri TK, Choi WW, Lei Y, et al. Cost implications of the rapid adoption of newer technologies for treating prostate cancer. J Clin Oncol (2011) 29:1517-24. doi:10.1200/JCO.2010.31.1217

12. Al-Mamgani A, van Putten WL, Heemsbergen WD, van Leenders GJ, Slot A, Dielwart MF, et al. Update of Dutch multicenter dose-escalation trial of radiotherapy for localized prostate cancer. Int J Radiat Oncol Biol Phys (2008) 72:980-8. doi:10.1016/j.ijrobp.2008.02.073 and review. JL - treated patients in review, manuscript preparation, and review. SA - treated patients in review, manuscript preparation, and review. MM - treated patients in review, manuscript preparation, and review. BG - treated patients in review, manuscript preparation, and review. JY - reviewed concept for research, supported physics analysis, manuscript preparation, and review. JF - supported physics analysis, manuscript preparation, and review.

\section{FUNDING}

No outside funding was utilized for this study.
13. Zietman AL, Bae K, Slater JD, Shipley WU, Efstathiou JA, Coen JJ, et al. Randomized trial comparing conventional-dose with high-dose conformal radiation therapy in early-stage adenocarcinoma of the prostate: long-term results from Proton Radiation Oncology Group/American College of Radiology 95-09. J Clin Oncol (2010) 28:1106-11. doi:10.1200/ JCO.2009.25.8475

14. Martinez AA, Gonzalez J, Ye H, Ghilezan M, Shetty S, Kernen K, et al. Dose escalation improves cancer-related events at 10 years for intermediate- and high-risk prostate cancer patients treated with hypofractionated high-doserate boost and external beam radiotherapy. Int J Radiat Oncol Biol Phys (2011) 79:363-70. doi:10.1016/j.ijrobp.2009.10.035

15. Kuban DA, Tucker SL, Dong L, Starkschall G, Huang EH, Cheung MR, et al. Long-term results of the M. D. Anderson randomized dose-escalation trial for prostate cancer. Int J Radiat Oncol Biol Phys (2008) 70:67-74. doi:10.1016/j. ijrobp.2007.06.054

16. Michalski JM, Yan Y, Watkins-Bruner D, Bosch WR, Winter K, Galvin JM, et al. Preliminary toxicity analysis of 3-dimensional conformal radiation therapy versus intensity modulated radiation therapy on the high-dose arm of the Radiation Therapy Oncology Group 0126 prostate cancer trial. Int J Radiat Oncol Biol Phys (2013) 87:932-8. doi:10.1016/j.ijrobp.2013.07.041

17. Michalski JM, Moughan J, Purdy J, Bosch W, Bahary JP, Lau HY, et al. A randomized trial of 79.2Gy versus 70.2Gy radiation therapy (RT) for localized prostate cancer. J Clin Oncol (2015) 33(Suppl 7):abstr4.

18. Widmark A. Phase III Study of HYPOfractionated RadioTherapy of Intermediate Risk Localised Prostate Cancer. Available from: http://www. isrctn.com/ISRCTN45905321

19. Lukka H, Hayter C, Julian JA, Warde P, Morris WJ, Gospodarowicz M, et al. Randomized trial comparing two fractionation schedules for patients with localized prostate cancer. J Clin Oncol (2005) 23(25):6132-8. doi:10.1200/ JCO.2005.06.153

20. Pollack A, Walker G, Horwitz EM, Price R, Feigenberg S, Konski AA, et al. Randomized trial of hypofractionated external-beam radiotherapy for prostate cancer. J Clin Oncol (2013) 31:3860-8. doi:10.1200/ JCO.2013.51.1972

21. Yeoh EE, Botten RJ, Butters J, Di Matteo AC, Holloway RH, Fowler J. Hypofractionated versus conventionally fractionated radiotherapy for prostate carcinoma: final results of phase III randomized trial. Int J Radiat Oncol Biol Phys (2011) 81:1271-8. doi:10.1016/j.ijrobp.2010.07.1984

22. Dearnaley D, Syndikus I, Sumo G, Bidmead M, Bloomfield D, Clark C, et al. Conventional versus hypofractionated high-dose intensity-modulated radiotherapy for prostate cancer: preliminary safety results from the $\mathrm{CHHiP}$ randomised controlled trial. Lancet Oncol (2012) 13:43-54. doi:10.1016/ S1470-2045(11)70293-5

23. Lee WR, Dignam JJ, Amin MB, Bruner DW, Low D, Swanson GP, et al. Randomized phase III noninferiority study comparing two radiotherapy fractionation schedules in patients with low-risk prostate cancer. J Clin Oncol (2016) 34(20):2325-32. doi:10.1200/JCO.2016.67.0448

24. RTOG. Radiation Therapy Oncology Group (RTOG) Protocol \#0938: A Randomized Phase II Trial of Hypofractionated Radiotherapy for Favorable Risk Prostate Cancer-RTOG CCOP Study. Philadelphia, PA: RTOG (2014). 
25. Freeman D, Dickerson G, Perman M. Multi-institutional registry for prostate cancer radiosurgery: a prospective observational clinical trial. Front Oncol (2015) 4:369. doi:10.3389/fonc.2014.00369

26. King CR, Brooks JD, Gill H, Presti JC. Long-term outcomes from a prospective trial of stereotactic body radiotherapy for low-risk prostate cancer. Int J Radiat Oncol Biol Phys (2012) 82:877-82. doi:10.1016/j. ijrobp.2010.11.054

27. Davis JN, Medbery C, Sharma S, Danish A, Mahadevan A. The RSSearch ${ }^{\mathrm{TM}}$ registry: patterns of care and outcomes research on patients treated with stereotactic radiosurgery and stereotactic body radiotherapy. Radiat Oncol (2013) 8:275. doi:10.1186/1748-717X-8-275

28. Katz AJ, Kang J. Stereotactic body radiation therapy for low-, intermediateand high-risk prostate cancer: disease control and quality of life at 9 years. J Clin Oncol (2016) 34(Suppl 2S):abstr 20.

29. Lawton CA, DeSilvio M, Roach M III, Uhl V, Kirsch R, Seider M, et al. An update of the phase III trial comparing whole pelvic to prostate only radiotherapy and neoadjuvant to adjuvant total androgen suppression: updated analysis of RTOG 94-13, with emphasis on unexpected hormone/radiation interactions. Int J Radiat Oncol Biol Phys (2007) 69:646-55. doi:10.1016/j. ijrobp.2007.04.003

30. Amini A, Jones BL, Yeh N, Rusthoven CG, Armstrong H, Kavanagh BD. Survival outcomes of whole-pelvic versus prostate-only radiation therapy for high-risk prostate cancer patients with use of the national cancer data base. Int J Radiat Oncol Biol Phys (2015) 93:1052-63. doi:10.1016/j. ijrobp.2015.09.006

31. Kim DWN, Straka C, Cho LC, Timmerman RD. Stereotactic body radiation therapy for prostate cancer: review of experience of a multicenter phase I/II dose-escalation study. Front Oncol (2014) 4:319. doi:10.3389/ fonc.2014.00319

32. Bruner DW, Hunt D, Michalski JM, Bosch WR, Galvin JM, Amin M, et al. Preliminary patient-reported outcomes analysis of 3-dimensional radiation therapy versus intensity-modulated radiation therapy on the high-dose arm of the Radiation Therapy Oncology Group (RTOG) 0126 prostate cancer trial. Cancer (2015)121(14):2422-30. doi:10.1002/cncr.29362

Conflict of Interest Statement: The authors declare that the research was conducted in the absence of any commercial or financial relationships that could be construed as a potential conflict of interest.

Copyright (c) 2016 Ricco, Manahan, Lanciano, Hanlon, Yang, Arrigo, Lamond, Feng, Mooreville, Garber and Brady. This is an open-access article distributed under the terms of the Creative Commons Attribution License (CC BY). The use, distribution or reproduction in other forums is permitted, provided the original author(s) or licensor are credited and that the original publication in this journal is cited, in accordance with accepted academic practice. No use, distribution or reproduction is permitted which does not comply with these terms. 